\title{
What Drives Country Differences in Cost of Alzheimer's Disease? An Explanation from Resource Use in the GERAS Study
}

Catherine Reed ${ }^{\mathrm{a}, *}$, Michael Happich ${ }^{\mathrm{b}}$, Josep Maria Argimon ${ }^{\mathrm{c}}$, Josep Maria Haro ${ }^{\mathrm{d}}$, Anders Wimo ${ }^{\mathrm{e}, \mathrm{f}}$, Giuseppe Bruno ${ }^{\mathrm{g}}$, Richard Dodel ${ }^{\mathrm{h}}$, Roy W. Jones ${ }^{\mathrm{i}}$, Bruno Vellas ${ }^{\mathrm{j}}$ and Mark Belger ${ }^{\mathrm{a}}$

${ }^{\mathrm{a}}$ Eli Lilly and Company Limited, Lilly Research Centre, Windlesham, UK

${ }^{\mathrm{b}}$ Lilly Deutschland GmbH, Bad Homburg, Germany

${ }^{\mathrm{c}}$ Divisió d'avaluació, Servei Català de la Salut, Barcelona, Spain

${ }^{\mathrm{d}}$ Parc Santari Sant Joan de Déu, CIBERSAM, Universitat de Barcelona, Sant Boi de Llobregat, Barcelona, Spain

${ }^{\mathrm{e}}$ KI Division of Neurogeriatrics, Department of Neurobiology, Care Sciences and Society, Karolinska Institute, Stockholm, Sweden

${ }^{\mathrm{f}}$ Centre for Research and Development, Uppsala University/Region of Gavleborg, Gävle, Sweden

' Clinica della Memoria, Department of Neurology \& Psychiatry, University of Rome "Sapienza",

Rome, Italy

${ }^{\mathrm{h}}$ Department of Neurology, Philipps-University, Marburg, Germany

${ }^{\mathrm{i}}$ RICE (The Research Institute for the Care of Older People), The RICE Centre, Royal United Hospital, Bath, UK

${ }^{\mathrm{j} G e r o n t o p o l e, ~ A l z h e i m e r ' s ~ D i s e a s e ~ R e s e a r c h ~ a n d ~ C l i n i c a l ~ C a r e, ~ I N S E R M ~ 1027, ~ T o u l o u s e ~ U n i v e r s i t y ~}$ Hospital, Toulouse, France

Accepted 5 February 2017

\section{Abstract.}

Background: Country differences in resource use and costs of Alzheimer's disease (AD) may be driven by differences in health care systems and resource availability.

Objective: To compare country resource utilization drivers of societal costs for AD dementia over 18 months.

Methods: GERAS is an observational study in France $(n=419)$, Germany $(n=550)$, and the UK $(n=526)$. Resource use of $\mathrm{AD}$ patients and caregivers contributing to $>1 \%$ of total societal costs (year 2010) was assessed for country differences, adjusting for participant characteristics.

\footnotetext{
*Correspondence to: Catherine Reed, Global Health Outcomes, Eli Lilly and Company, Erl Wood Manor, Sunninghill Road, Windlesham, Surrey GU20 6PH, UK. Tel.: +44 1276483243 ; Fax: +44 1276 483192; E-mail: reed_catherine@lilly.com.
} 
Results: Mean 18-month societal costs per patient were France $€ 33,339$, Germany $€ 38,197$, and UK $€ 37,899$ ( $£ 32,501)$. Caregiver time spent on basic and instrumental activities of daily living (ADL) contributed the most to societal costs (54\% France, 64\% Germany, 65\% UK). Caregivers in France spent less time on ADL than UK caregivers and missed fewer work days than in other countries. Compared with other countries, patients in France used more community care services overall and were more likely to use home aid. Patients in Germany were least likely to use temporary accommodation or to be institutionalized at 18 months. UK caregivers spent the most time on instrumental ADL, UK patients used fewest outpatient resources, and UK patients/caregivers were most likely to receive financial support.

Conclusion: Caregiver time on ADL contributed the most to societal costs and differed across countries, possibly due to use of community care services and institutionalization. Other resources had different patterns of use across countries, reflecting country-specific health and social care systems.

Keywords: Activities of daily living, Alzheimer's disease, caregivers, costs, health resources

\section{INTRODUCTION}

Total societal costs of caring for patients with Alzheimer's disease (AD) dementia vary across countries or regions of Europe with different health care systems [1, 2]. Available cost studies from several European countries show a strong positive relationship between disease severity and total costs of care [1, 3-8]. Informal care costs form the major component of societal costs for community-dwelling $\mathrm{AD}$ dementia patients [8-11], and the cost of institutional care is the other main cost driver in the long-term care of patients with AD dementia [12].

Differences between countries in total societal costs of caring for people with $\mathrm{AD}$ dementia have been attributed to differences in study methodology and/or health care systems [1]. Differences exist in resource utilization between countries [2], although there may also be regional variations in the delivery of care within countries.

Differences in resource use between countries in the context of their health care system structure and resource availability are important to understand as this has a direct influence on costs. However, few studies have examined resource use in multiple countries, have a large sample size with a prospective follow-up, or use standardized measures of resource use [1]. Resource use has been studied within the mild and moderate $\mathrm{AD}$ dementia population [2] rather than across the full range of AD dementia stages.

The objective of this study was to compare resource utilization over 18 months for community-dwelling $\mathrm{AD}$ dementia patients across the three countries in the GERAS study (France, Germany, and the UK) [8], focusing on the individual resource use items with the greatest contribution to country-specific total societal costs. As total societal costs were unadjusted for disease severity and would be influenced by the percentage of patients in each severity group as well as by country differences in costs of individual resources, we have focused on the adjusted resource use item analysis rather than costs.

\section{METHODS}

\section{Study design and population}

GERAS is an 18-month, multicenter, prospective, non-interventional cohort study conducted in France, Germany, and the UK, designed to evaluate the costs and resource use associated with $\mathrm{AD}$ dementia for community-dwelling patients and their caregivers [8]. Full details of the study design, patient characteristics, and baseline costs and resource use for each of the participating countries have been reported [8]. Participants were enrolled between October 2010 and September 2011.

Inclusion criteria were community-dwelling patients, aged at least 55 years, presenting within the normal course of clinical care, diagnosed with probable $\mathrm{AD}$ dementia according to the National Institute of Neurological and Communicative Disorders and Stroke and the Alzheimer's Disease and Related Disorders Association criteria [13], with a Mini-Mental State Examination (MMSE) score [14] of $\leq 26$ points, and with an informal caregiver who was willing to participate in the study and undertake responsibility for the patient for at least 6 months of the year.

Information was collected for patients and caregivers at the baseline visit and at 6, 12, and 18 months during routine care visits. Data collected included sociodemographics, comorbidities, medications, and health-related quality of life. Additional patient assessments included cognitive function (assessed using the MMSE and the cognitive subscale of 
the Alzheimer's Disease Assessment Scale [ADAScog] [15]), functional ability (assessed using the Alzheimer's Disease Co-operative Study Activities of Daily Living Inventory [ADCS-ADL] [16]), and behavioral and psychological symptoms (assessed using the Neuropsychiatric Inventory [NPI] [17]). Caregivers also completed the Zarit Burden Interview (ZBI), which provides a measure of caregiver burden [18].

\section{Resource use}

Resource use by patients and their informal caregivers was captured using the Resource Utilization in Dementia (RUD) instrument [19], version RUD Complete 3.1. This standardized instrument is widely used for resource use data collection in dementia, has been validated for use in different care settings (i.e., community-living and institutionalized patients) [20, 21 , and enables comparison of costs of care across countries with differing health care provisions [22]. The RUD instrument was administered via an interview with the primary informal caregiver.

Resource use items collected included health care (e.g., outpatient visits, hospital stays, emergency room visits), community care services (district nurse, home aid, food delivery, day care, transportation, other), changes to patient living accommodation (permanent, temporary; institutionalization), caregiver work status (working for pay, missing work days), and caregiver time (i.e., time spent caring for the patient by the primary caregiver). Outpatient visits included visits to a general practitioner (GP), geriatrician, psychiatrist, neurologist, physiotherapist, occupational therapist, social worker, psychologist, or other health care professional.

Caregiver time spent on giving informal care was recorded as the time spent by the caregiver on assisting the patient with basic activities of daily living (ADL; e.g., eating, bathing, dressing, using the bathroom), instrumental ADL (e.g., housework, shopping, medication use, financial management), and supervision (i.e., preventing dangerous events).

The recall period varied for different resource use items in the RUD and differed for the baseline and follow-up visits. All baseline resource use was measured as activity in the previous month. Resource use at each post-baseline visit is reported for the time period and units collected in the RUD (e.g., caregiver time is reported as hours per month, while community care visits are reported as the number of visits over the previous 3 months).
Additional data collected from caregivers during the interviews included patient medications, out-of-pocket expenses, and additional financial support received (e.g., whether the patient or caregiver receives money from the government or an insurance company for assistance or for being a caregiver).

Further information on resource use calculation over 18 months is provided in the supplemental material.

\section{Cost estimation}

For each country, monthly cost values were estimated by applying country-specific unit costs of services and products (2010 values) to the health and social care resource use collected over the 18-month follow-up period. The unit costs for institutionalization are given in Supplementary Table 1. For all other resource use items, full details of the unit costs applied and their sources for each country have already been reported (see the supplementary material in Wimo et al. [8]) but are also given in Supplementary Table 1 . All UK costs in pounds sterling $(£)$ were converted to Euros $(€)$ using the conversion rate $£ 1=€ 1.1661$, calculated as the average monthly exchange rate for 2010, as reported previously [8].

Total societal costs for each country were calculated using an opportunity cost approach taking into account productivity loss for working caregivers and lost leisure time for non-working caregivers. Further information on cost calculation is provided in the Supplemental Material.

\section{Statistical analysis}

Demographics and baseline characteristics were summarized using descriptive statistics and were based on non-missing observations. Comparisons between countries used Cochran-Mantel-Haenszel (CMH) tests for categorical data, stratified by MMSE severity groups, and Analysis of Variance (ANOVA) with independent factors for MMSE severity and country for continuous data.

The costs of all individual resource use items at each follow-up visit $(6,12$, and 18 months) and for the overall 18-month period were summarized for each country to identify the resource use items with the greatest contribution to total societal costs (see Supplementary Table 2). From this analysis, the following items were included in the analysis of resource use differences between countries: caregiver time, community care services, hospital stays, AD 
medications, financial support received, temporary accommodation, outpatient visits, institutionalization, and missing work days. With the exception of missing work days, these items represented a minimum of $3 \%$ of country total societal costs in at least one country in at least one 6-month visit (see Supplementary Table 2).

For community care services, each type of service (district nurse, home aid, food delivery, day care, transportation, other) was analyzed individually as well as being analyzed as a single combined item. Unit costs based on the average from all three countries for each service were applied to each service to give an overall score, which was then analyzed to test for differences between countries. Use of average unit costs is a method for weighting the relative importance of each service (e.g., a visit from a district nurse has greater weighting than a food delivery) but allows testing for country differences independently of differences in costs of services across countries. Outpatient visits (GP, geriatrician, psychiatrist, neurologist, physiotherapist, occupational therapist, social worker, psychologist, other) were treated in the same way, with average unit costs being assigned against each type of outpatient visit to give a weighted score.

Differences in resource use between countries were analyzed using various models (Table 1), which were selected on the basis of the distributional assumptions for each resource use item. For each model, the following factors were included (in addition to country): patient age, patient sex, MMSE severity group (mild, moderate, moderately severe/severe $[\mathrm{MS} / \mathrm{S}]$ ), number of patient comorbidities, baseline total ADL score, caregiver age, caregiver relationship (spouse yes/no), caregiver working for pay, and baseline score of the outcome measure (i.e., resource utilization item). In some of the repeated visits zero-inflated models, certain factors had to be removed to avoid issues of convergence of the algorithms for the models.

For the primary analysis, country differences were assessed through analysis of each resource use outcome measure by repeated measures models (using an 'exchangeable' correlation structure) of resource use at each 6-month visit, which uses all available data and models resource use at each 6-month visit. This method takes account of the fact that the measures at different time periods are not independent. Repeated measures models for zero-inflated negative binomials are not an option through the generalized linear models (GLMs) in SAS 9.2. A zero-inflated nega- tive binomial model was run including visit as one of the factors. This type of model assumed independence between each visit. As a sensitivity analysis, the effect of this assumption was assessed by running a repeated measures negative binomial model. The results of this sensitivity analysis are not reported but were consistent with the main analysis.

Data from the repeated measures models with gamma distribution and log-link function (caregiver time, 3-month weighted score for community care services, and 3-month weighted score for outpatient visits) are presented as least square (LS) means and $95 \%$ confidence limits (CL). Data from the zero-inflated negative binomial repeated visits models (community care services, outpatient visits) are presented as LS mean number of visits for those with a non-zero response $(95 \% \mathrm{CL})$. For ease of interpretation, the odds ratio (OR) of no visits (and 95\% CL) have been inverted; therefore, an OR $>1$ can be interpreted as a greater likelihood of having a visit compared with the UK (reference country). Data from the repeated measures logistic regression models (temporary accommodation, AD medication, financial support received) are presented as OR (95\% CL). An OR $>1$ can be interpreted as an increased likelihood of that outcome compared with the UK. Data from the GLM repeated measures model with a negative binomial distribution (caregiver missing work days, patient hospital stays) are presented as LS means (95\% CL) and OR (95\% CL). All $p$-values are for country comparisons.

Differences in times to institutionalization were tested using a proportional hazards model including country and baseline characteristics as above, and are reported as hazard ratios (HRs) with $95 \% \mathrm{CL}$ and $p$-value.

Country differences for each resource use item were also analyzed as a sensitivity analysis by modeling 18-month resource use, which was calculated as the sum of resource use at each 6-month visit and was, therefore, limited to patients who had data for all three follow-up visits (i.e., a completers analysis). We only describe the results that differed from those in the primary analysis.

All data were analyzed using SAS software, version 9.2 (SAS Institute, Cary, North Carolina, USA).

\section{RESULTS}

Overall, 1,495 patients with $\mathrm{AD}$ dementia were analyzed at baseline: 419 patients in France, 550 patients in Germany, and 526 patients in the UK. 
Table 1

Models used to analyze resource use items

\begin{tabular}{|c|c|c|c|}
\hline Resource utilization item & Data Type & Distributional assumption & Model used \\
\hline Caregiver time & Continuous & Gamma & GLM - gamma distribution with log link \\
\hline \multicolumn{4}{|l|}{ Community care services } \\
\hline a. District nurse & Count & Negative binomial & \\
\hline b. Home aid & Count & Negative binomial & \\
\hline c. Food delivery & Count & Negative binomial & \\
\hline d. Day care & Count & Negative binomial & GLM - zero-inflated negative binomial model \\
\hline e. Transportation & Count & Negative binomial & \\
\hline f. Other & Count & Negative binomial & \\
\hline Weighted score & Continuous & Gamma & GLM - gamma distribution with log link \\
\hline Temporary accommodation & Binary & Binomial & $\begin{array}{l}\text { Logistic regression model (patient spent nights in } \\
\text { temporary accommodation, yes/no) }\end{array}$ \\
\hline Institutionalization & Time to Event & Proportional hazards & Cox proportional hazards model \\
\hline AD medications & Binary & Binomial & $\begin{array}{l}\text { Logistic regression model (patient received AD } \\
\text { medication, yes/no) }\end{array}$ \\
\hline Caregiver missing work days & Count & Negative binomial & $\begin{array}{l}\text { Analysis restricted to caregivers who work. } \\
\text { GLM - zero-inflated negative binomial model }\end{array}$ \\
\hline Hospital stay & Count & Negative binomial & GLM - zero-inflated negative binomial model \\
\hline \multicolumn{4}{|l|}{ Outpatient visits } \\
\hline a. General practitioner & Count & Negative binomial & \\
\hline b. Geriatrician & Count & Negative binomial & \\
\hline c. Psychiatrist & Count & Negative binomial & \\
\hline d. Neurologist & Count & Negative binomial & \\
\hline e. Physiotherapist & Count & Negative binomial & GLM - zero-inflated negative binomial model \\
\hline f. Occupational therapist & Count & Negative binomial & \\
\hline g. Social worker & Count & Negative binomial & \\
\hline h. Psychologist & Count & Negative binomial & \\
\hline i. Other & Count & Negative binomial & \\
\hline Weighted score & Continuous & Gamma & GLM - gamma distribution with log link \\
\hline Financial support received & Binary & Binomial & $\begin{array}{l}\text { Logistic regression model (patient received } \\
\text { financial support, yes/no) }\end{array}$ \\
\hline
\end{tabular}

AD, Alzheimer's disease; GLM, generalized linear model.

The baseline characteristics of the patients and caregivers participating in the GERAS study are summarized by country in Table 2 . Differences across countries were seen for patient age, sex, time since $\mathrm{AD}$ dementia diagnosis, living alone in their own home, MMSE score, ADCS-ADL score, and mean number of comorbidities. Across countries, caregivers differed for age, sex, and whether they were the patient's spouse.

Over 18 months of follow-up, 130 (31\%) patients in France discontinued from the study due to institutionalization $(n=65 ; 50 \%)$, death $(n=21 ; 16 \%)$, or other reasons $(n=44 ; 34 \%$; including lost to followup, physician decision, patient decision). In Germany, $169(31 \%)$ patients discontinued due to institutionalization $(n=55 ; 33 \%)$, death $(n=31 ; 18 \%)$, or other reasons $(n=83 ; 49 \%)$. In the UK, 185 (35\%) patients discontinued due to institutionalization $(n=94 ; 51 \%)$, death $(n=40 ; 22 \%)$, or other reasons $(n=51 ; 28 \%)$.

For patients with completed follow-up visits, missing data on individual items was minimal $(<1 \%)$.

\section{Total societal costs}

Estimated mean total societal costs per patient over 18 months by country are summarized in Fig. 1. For the whole study cohort, mean total costs were highest in Germany $(€ 38,197 ; 95 \% \mathrm{CL}$ : $36,077-40,375)$ and lowest in France $(€ 33,339$; 95\% CL: 31,172-35,548). When unadjusted country costs were compared by disease severity, mean total costs for patients with mild $\mathrm{AD}$ dementia at baseline were highest in the UK $(€ 30,161 ; 95 \%$ CL: $27,338-33,279)$, whereas Germany had the highest mean costs for patients with moderate $(€ 42,430$; 95\% CL: 38,613-46,723) and MS/S AD dementia $(€ 50,947 ; 95 \%$ CL: 47,506-54,563).

\section{Unadjusted costs of resource use items and resource utilization by country}

The percentage contribution to total societal costs of individual resource use items at the 6-, 12-, and 18 -month visits in each country and for the over- 
Table 2

Summary of patient and caregiver characteristics at baseline by country

\begin{tabular}{lccrr}
\hline Baseline characteristic & \multicolumn{3}{c}{ Country } & \multirow{2}{*}{$p$-value } \\
\cline { 2 - 3 } & France & Germany & UK & \\
\hline Patients & 419 & & & \\
Number of patients & $79.4(6.81)$ & $75.2(7.55)$ & $78.5(7.79)$ & $<0.001$ \\
Age, years & 62.3 & 49.6 & 54.2 & $<0.001$ \\
Sex (\% female) & $2.5(2.41)$ & $2.0(2.14)$ & $2.2(2.13)$ & 0.009 \\
Years since diagnosis & 20.3 & 16.2 & 15.0 & $<0.001$ \\
Living alone, own home (\%) & $17.2(5.73)$ & $17.7(6.72)$ & $17.3(6.40)$ & $<0.001$ \\
Baseline MMSE score (range 0-30) & $47.4(18.16)$ & $45.5(21.92)$ & $46.8(17.69)$ & 0.001 \\
Baseline total ADL score (range 0-78) & $1.8(1.27)$ & $1.4(1.19)$ & $1.2(1.15)$ & $<0.001$ \\
Number of patient comorbidities & & & & \\
Caregivers & $418^{\mathrm{a}}$ & $549^{\mathrm{a}}$ & 526 & 0.001 \\
Number of caregivers & $67.9(12.39)$ & $65.9(11.78)$ & $68.3(11.90)$ & 0.004 \\
Age, years & 62.4 & 67.8 & 61.8 & 0.016 \\
Sex (\% female) & 61.7 & 67.6 & 67.5 & 0.457 \\
Caregiver relationship (\% spouse) & 21.5 & 28.6 & 20.5 & \\
Caregiver working for pay (\%) & & & \\
\hline
\end{tabular}

Data are presented as means (SD) unless otherwise indicated. ADL, Activities of Daily Living; MMSE, Mini-Mental State Examination. $p$-values for comparison between countries (Cochran-Mantel-Haenszel tests for categorical variables and ANOVA with independent factors for MMSE severity and country for continuous variables). ${ }^{\mathrm{a}}$ Data missing for one caregiver.

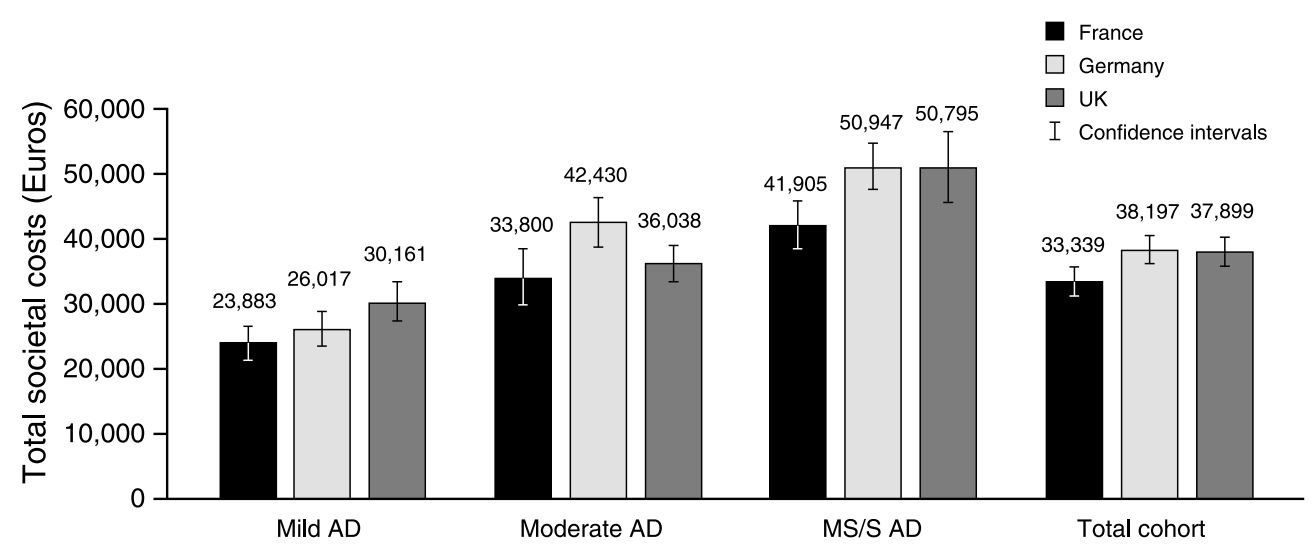

Fig. 1. Estimated mean total societal costs per patient over 18 months by country. UK data were converted to Euros using conversion rate $£ 1=€ 1.1661$. AD, Alzheimer's disease, MS/S, moderately severe/severe.

all 18-month period in each country (Supplementary Table 2) showed that caregiver time was the resource use item that exerted the highest cost contribution in all three countries, accounting for $54 \%$ of the total costs in France, 64\% in Germany, and 65\% in the UK for the overall 18-month period in patients with resource use data at all three follow-up visits. The relative contribution of other resource use items to total costs was much lower and varied between countries. Notably, community care services resulted in a higher contribution to total costs in France $(15 \%)$ than in Germany (4\%) or the UK (7\%). Also, additional financial support accounted for $14 \%$ of total costs in the UK compared with 4\% in France and 5\% in Germany (Supplementary Table 2). Over 18 months, institutionalization rates were $15.5 \%, 10.0 \%$, and $17.3 \%$ in France, Germany, and the UK, respectively, and in all three countries, the costs of institutionalization increased as a percentage of total societal costs over time at each 6-month visit.

\section{Adjusted country differences in resource use over 18 months}

\section{Repeated measures models}

Table 3 presents the comparisons between countries for resource utilization from the repeated measures analyses. Caregiver time spent on basic ADL differed across countries $(p<0.001)$ and was lower in France $(24.4 \mathrm{~h} /$ month) than in the UK 
Table 3

Country differences for each resource use item: results from repeated measures models

\begin{tabular}{|c|c|c|c|c|c|}
\hline \multirow[t]{2}{*}{ Resource use item } & & \multicolumn{3}{|c|}{ Country } & \multirow[t]{2}{*}{$p$-value } \\
\hline & & France & Germany & UK & \\
\hline \multicolumn{6}{|l|}{ Caregiver time ( $h /$ month) } \\
\hline Basic ADL & LS mean $(95 \% \mathrm{CL})$ & $24.4(20.4-29.2)^{\mathrm{d}}$ & $32.8(28.0-38.4)$ & $36.4(30.8-43.1)$ & $<0.001$ \\
\hline Instrumental ADL & LS mean $(95 \% \mathrm{CL})$ & $59.5(53.9-65.7)^{\mathrm{d}}$ & $66.5(61.1-72.4)^{\mathrm{d}}$ & $89.3(82.0-97.3)$ & $<0.001$ \\
\hline Basic + instrumental ADL & LS mean $(95 \% \mathrm{CL})$ & $88.6(80.1-98.0)^{\mathrm{d}}$ & $101.3(92.8-110.5)^{\mathrm{d}}$ & $125.4(115.9-135.6)$ & $<0.001$ \\
\hline \multicolumn{6}{|c|}{ Community care services (in past 3 months) ${ }^{\mathrm{a}}$} \\
\hline \multirow[t]{2}{*}{ District nurse } & OR $(95 \% \mathrm{CL})$ & $1.52(0.94-2.45)^{\mathrm{e}}$ & $0.73(0.45-1.19)^{\mathrm{f}}$ & 1.00 & $<0.001$ \\
\hline & LS Mean (95\% CL) & $39.9(34.3-46.5)^{\mathrm{d}}$ & $44.6(37.6-52.9)^{\mathrm{d}}$ & $2.5(2.1-3.1)$ & $<0.001$ \\
\hline \multirow[t]{2}{*}{ Home aid } & OR $(95 \% \mathrm{CL})$ & $4.79(3.17-7.24)^{\mathrm{d}, \mathrm{e}}$ & $1.00(0.64-1.57)^{\mathrm{f}}$ & 1.00 & $<0.001$ \\
\hline & LS Mean (95\% CL) & $32.2(29.1-35.6)^{\mathrm{d}, \mathrm{e}}$ & $22.3(19.3-25.8)^{\mathrm{d}, \mathrm{f}}$ & $43.5(38.3-49.4)$ & $<0.001$ \\
\hline \multirow[t]{2}{*}{ Food delivery } & OR $(95 \%$ CL) & $1.00(0.47-2.12)$ & $1.28(0.61-2.69)$ & 1.00 & 0.759 \\
\hline & LS Mean (95\% CL) & $41.6(30.7-56.5)^{\mathrm{d}}$ & $40.7(30.9-53.5)^{\mathrm{d}}$ & $18.7(13.1-26.8)$ & $<0.001$ \\
\hline \multirow[t]{2}{*}{ Day care } & OR $(95 \%$ CL $)$ & $0.87(0.55-1.37)$ & $0.76(0.50-1.16)$ & 1.00 & $<0.001$ \\
\hline & LS Mean (95\% CL) & $16.2(14.2-18.5)^{\mathrm{e}}$ & $21.3(18.5-24.5)^{\mathrm{f}}$ & $17.2(15.3-19.5)$ & 0.004 \\
\hline \multirow[t]{2}{*}{ Transportation } & OR $(95 \%$ CL) & $1.39(0.83-2.30)^{\mathrm{e}}$ & $0.54(0.31-0.95)^{\mathrm{d}, \mathrm{f}}$ & 1.00 & $<0.001$ \\
\hline & LS Mean (95\% CL) & $10.9(8.6-13.8)^{\mathrm{e}}$ & $22.4(16.8-30.0)^{\mathrm{f}}$ & $16.9(12.9-22.2)$ & $<0.001$ \\
\hline \multirow[t]{2}{*}{ Other } & OR $(95 \%$ CL) & $0.57(0.29-1.11)$ & $0.58(0.31-1.06)$ & 1.00 & $<0.001$ \\
\hline & LS Mean (95\% CL) & $13.1(8.9-19.3)$ & $13.6(9.2-20.1)$ & $10.6(7.5-15.1)$ & 0.390 \\
\hline \multicolumn{2}{|l|}{ 3-month weighted score } & $507.8(419.3-614.9)^{\mathrm{d}, \mathrm{e}}$ & $287.4(229.3-360.1)^{\mathrm{f}}$ & $270.3(221.9-329.2)$ & $<0.001$ \\
\hline \multicolumn{6}{|l|}{$\begin{array}{l}\text { lemporary accommodation } \\
\text { (in past } 6 \text { months) }\end{array}$} \\
\hline $\mathrm{AD}$ medication (in past 6 months) b $^{\mathrm{b}}$ & OR $(95 \% \mathrm{CL})$ & $1.38(0.75-2.53)$ & $1.23(0.68-2.22)$ & 1.00 & 0.573 \\
\hline \multirow{2}{*}{$\begin{array}{l}\text { Caregiver missing work days } \\
\text { (in past } 6 \text { months) }\end{array}$} & OR $(95 \% \mathrm{CL})$ & $0.31(0.04-2.43)$ & $0.19(0.04-0.85)^{\mathrm{d}}$ & 1.00 & 0.003 \\
\hline & LS Mean $(95 \%$ CL) & $2.1(1.3-3.6)^{\mathrm{d}, \mathrm{e}}$ & $5.6(3.9-8.0)^{\mathrm{f}}$ & $5.6(4.0-7.9)$ & $<0.001$ \\
\hline \multirow[t]{2}{*}{ Hospital stays (in past 6 months) ${ }^{\mathrm{a}}$} & OR $(95 \%$ CL) & $0.66(0.39-1.11)$ & $0.81(0.49-1.32)$ & 1.00 & 0.187 \\
\hline & LS Mean $(95 \%$ CL) & $15.4(10.9-22.0)^{\mathrm{d}, \mathrm{e}}$ & $7.2(5.4-9.5)^{\mathrm{f}}$ & $5.9(4.3-8.1)$ & $<0.001$ \\
\hline \multicolumn{6}{|c|}{ Outpatient visits (in past 3 months) ${ }^{\mathrm{a}}$} \\
\hline General practitioner ${ }^{\mathrm{c}}$ & LS Mean $(95 \% \mathrm{CL})$ & $2.0(1.8-2.2)^{\mathrm{d}, \mathrm{e}}$ & $2.5(2.2-2.8)^{\mathrm{d}, \mathrm{f}}$ & $1.5(1.3-1.7)$ & $<0.001$ \\
\hline \multirow{2}{*}{ Geriatrician } & OR $(95 \% \mathrm{CL})$ & $6.42(0.88-46.71)^{\mathrm{e}}$ & $0.12(0.02-0.63)^{\mathrm{d}, \mathrm{f}}$ & 1.00 & $<0.001$ \\
\hline & LS Mean (95\% CL) & $0.4(0.2-0.8)^{\mathrm{e}}$ & $3.1(1.6-6.0)^{\mathrm{d}, \mathrm{f}}$ & $0.5(0.2-1.5)$ & $<0.001$ \\
\hline Psychiatrist ${ }^{\mathrm{c}}$ & LS Mean (95\% CL) & $0.04(0.02-0.09)^{\mathrm{d}}$ & $0.1(0.08-0.14)$ & $0.2(0.1-0.2)$ & $<0.001$ \\
\hline Neurologist & LS Mean (95\% CL) & $0.5(0.4-0.8)$ & $0.8(0.6-1.0)$ & $0.3(0.1-1.5)$ & 0.092 \\
\hline \multirow[t]{2}{*}{ Physiotherapist } & OR $(95 \%$ CL) & $2.44(1.25-4.79)^{\mathrm{d}}$ & $2.52(1.32-4.81)^{\mathrm{d}}$ & 1.00 & 0.003 \\
\hline & LS Mean (95\% CL) & $20.5(16.9-24.9)^{\mathrm{d}}$ & $17.8(14.9-21.3)^{\mathrm{d}}$ & $2.8(2.1-3.8)$ & $<0.001$ \\
\hline \multirow[t]{2}{*}{ Occupational therapist } & OR $(95 \% \mathrm{CL})$ & $0.73(0.28-1.94)^{\mathrm{e}}$ & $1.07(0.47-2.46)^{\mathrm{f}}$ & 1.00 & 0.009 \\
\hline & LS Mean (95\% CL) & $6.8(4.3-10.7)^{\mathrm{d}, \mathrm{e}}$ & $17.1(13.1-22.3)^{\mathrm{d}, \mathrm{f}}$ & $1.7(1.1-2.6)$ & $<0.001$ \\
\hline \multirow[t]{2}{*}{ Social worker } & OR $(95 \%$ CL) & $1.50(0.40-5.56)^{\mathrm{e}}$ & $0.03(0.01-0.13)^{\mathrm{d}, \mathrm{f}}$ & 1.00 & $<0.001$ \\
\hline & LS Mean (95\% CL) & $0.1(0.1-0.3)^{\mathrm{e}}$ & $31.8(11.4-88.4)^{\mathrm{d}, \mathrm{f}}$ & $0.5(0.3-0.9)$ & $<0.001$ \\
\hline Psychologist & LS Mean (95\% CL) & $2.8(0.8-10.0)$ & $3.7(0.9-15.6)$ & $1.9(0.2-18.8)$ & 0.822 \\
\hline \multirow[t]{2}{*}{ Other } & OR $(95 \%$ CL) & $0.24(0.09-0.65)^{\mathrm{d}}$ & $0.21(0.07-0.59)^{\mathrm{d}}$ & 1.00 & $<0.001$ \\
\hline & LS Mean (95\% CL) & $4.3(3.5-5.2)^{\mathrm{d}, \mathrm{e}}$ & $1.2(1.0-1.5)^{\mathrm{f}}$ & $1.1(1.0-1.3)$ & $<0.001$ \\
\hline 3-month weighted score & & $232.0(194.9-276.2)^{\mathrm{d}}$ & $229.0(194.1-270.1)^{\mathrm{d}}$ & $124.6(104.9-147.9)$ & $<0.001$ \\
\hline $\begin{array}{l}\text { Financial support received by } \\
\text { caregiver/patient } \\
\text { (in past } 6 \text { months) }{ }^{b}\end{array}$ & OR $(95 \%$ CL) & $0.10(0.07-0.16)^{\mathrm{d}}$ & $0.35(0.25-0.49)^{\mathrm{d}}$ & 1.00 & $<0.001$ \\
\hline
\end{tabular}

$p$-values are for the comparison across countries. AD, Alzheimer's disease; ADL, activities of daily living; CL, confidence limit; LS, least squares; OR, odds ratio. ${ }^{a}$ An OR relates to the likelihood of using this resource use item. An OR >1 can be interpreted as a greater likelihood of using this resource use item compared with the UK. LS means give the activity for those patients using this resource use item; e.g., number of visits from a district nurse, number of caregiver missing work days, or number of days spent in hospital in the past 6 months. ${ }^{\mathrm{b}}$ An OR $>1$ can be interpreted as an increased likelihood of spending time in temporary accommodation, having AD medication or receiving additional financial support, compared with the UK. ${ }^{\mathrm{c}} \mathrm{LS}$ means are from the repeated measures negative binomial model. ${ }^{\mathrm{d}}$ Significantly different from

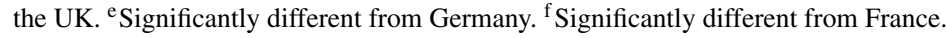

(36.4 h/month). Caregiver time spent on instrumental ADL also differed across countries $(p<0.001)$ and was higher in the UK ( $89.3 \mathrm{~h} /$ month) than in France (59.5 h/month) or Germany (66.5 h/month). Care- giver time spent on basic + instrumental ADL was higher in the UK (125.4 h/month) than in France or Germany (88.6 and $101.3 \mathrm{~h} /$ month, respectively; $p<0.001)$. 
For community care services, the 3-month weighted score shows that patients in France used more community care services than patients in the other two countries (Table 3). The ORs for the individual services show that patients in France were more likely to receive district nurse visits than patients in Germany and were more likely to receive home aid visits than those in the other two countries. Use of transportation services was less likely for patients in Germany than for those in the UK or France. The LS means for the individual community care service items show that if the service was used, patients in the UK had fewer district nurse visits and food delivery, but more home aid services than patients in the other two countries. Patients in Germany received more day care and transportation services than those using these services in France.

The results of the repeated measures model (Table 3) also show that patients in Germany were less likely to have spent time in temporary accommodation since the last visit than patients in the UK (OR $=0.40$; 95\% CL: $0.28-0.59 ; p<0.001$ ) or France (OR versus UK $=1.29$; 95\% CL: 0.94-1.78). Use of AD medication (versus no use) did not differ between countries $(p=0.57)$. Further analyses showed that memantine only use was more likely in France $(\mathrm{OR}=2.26$; 95\% CL: 1.07-4.78) and Germany $(\mathrm{OR}=1.88 ; 95 \% \mathrm{CL}: 0.86-4.12)$ than in the UK, although it did not reach statistical significance $(p=0.08)$. Memantine use together with acetylcholinesterase inhibitors was more likely in France $(\mathrm{OR}=1.57$; 95\% CL: 0.85-2.91) than in Germany $(\mathrm{OR}=0.58$; 95\% CL: $0.32-1.06 ; p=0.01)$.

Caregivers in Germany were less likely to have missed work than caregivers from the UK. If they missed work, French caregivers missed fewer working days than caregivers in the other two countries (Table 3).

If French patients were taken into hospital, the number of days in the past 6 months they stayed in hospital was greater than for patients in Germany or the UK (Table 3). No difference in the likelihood of being hospitalized was observed between the three countries $(p=0.187)$.

Patients and caregivers in France and Germany were less likely to receive financial support than those in the UK $(\mathrm{OR}=0.10$ and 0.35 for France and Germany, respectively; $p<0.001$ ). The 3 -month weighted score for outpatient resources showed that patients in the UK used fewer outpatient resources than patients in France or Germany (weighted scores: 125 versus 232 and 229 , respectively; $p<0.001$ ). UK patients had fewer GP visits than those in France and Germany, while German patients had a higher number of GP visits than French patients. For patients who saw a geriatrician or an occupational therapist, those in Germany had more frequent visits to these health care professionals than patients in the other two countries. UK patients were less likely to see a physiotherapist than those in the other two countries and had fewer visits to a physiotherapist if seen by one. German patients were less likely to have been referred to a social worker, but when they saw one, the number of visits was significantly greater than for patients in France and the UK. French patients had fewer visits to a psychiatrist than those in the UK.

Proportional hazards models with UK as the reference country showed the likelihood of institutionalization at 18 months was lower for patients in Germany (HR $=0.59 ; 95 \%$ CL: $0.41-0.84 ; p=0.014)$ but similar for French patients $(\mathrm{HR}=0.84 ; 95 \% \mathrm{CL}$ : $0.60-1.18)$.

\section{Sensitivity analysis: Models of 18-month resource use}

Country comparisons for resource use items from the 18-month resource use models (completer's analysis) gave very similar results. The only difference from the repeated measures models was that LS mean caregiver time spent on basic ADL did not differ between France (425.2 h; 95\% CL: 306.9-588.9), Germany (569.8h; 95\% CL: 428.4-757.9), and the UK (615.0 h; 95\% CL: 456.8-827.9); $p=0.134$.

\section{DISCUSSION}

Few studies have examined longitudinal resource use and the cost of caring for patients with $\mathrm{AD}$ dementia or examined the differences in resource utilization between countries. Our results from the GERAS study of community-dwelling AD dementia patients and their caregivers showed that informal caregiver time was the resource item with the greatest contribution to total societal costs at each level of $\mathrm{AD}$ dementia severity, accounting for $54-65 \%$ of the 18 -month costs in all three countries (Supplementary Table 2).

Country differences in societal costs may be due to differential unit costs being applied and/or to differences in resource utilization, which are influenced by the health and social care systems of each country as well as the availability of and access to care providers. 
Table 4

Comparison of health care systems in France, Germany, and the UK

\begin{tabular}{|c|c|c|}
\hline & France & Germany \\
\hline \multicolumn{3}{|l|}{ General $^{\mathrm{a}}$} \\
\hline $\begin{array}{l}\text { Organization of } \\
\text { health care system }\end{array}$ & $\begin{array}{l}\text { Mix of public and private } \\
\text { providers; SHI system, with all } \\
\text { SHI insurers incorporated into } \\
\text { single national exchange [53] }\end{array}$ & $\begin{array}{l}\text { Health care (medical care) and } \\
\text { social care operate as separate } \\
\text { systems with different financing } \\
\text { structures } \\
\text { SHI system, with } 131 \text { competing } \\
\text { SHI insurers ("sickness funds" in } \\
\text { a national exchange); high } \\
\text { income can opt out for private } \\
\text { coverage [57] }\end{array}$ \\
\hline
\end{tabular}
UK

NHS: provides care including hospital and physician services and prescription drugs to all residents (T40)

The organizational structure and governance of the health care system is different in each of the four countries of the UK (England, Scotland, Wales, and Northern Ireland), and they have diverging policies for health services [64]

\begin{tabular}{|c|c|c|c|}
\hline $\begin{array}{l}\text { Public system } \\
\text { financing }\end{array}$ & $\begin{array}{l}\text { Employer/employee earmarked } \\
\text { income and payroll tax; general } \\
\text { tax revenue, earmarked taxes }\end{array}$ & $\begin{array}{l}\text { Employer/employee earmarked } \\
\text { payroll tax; general tax revenue }\end{array}$ & $\begin{array}{l}\text { General tax revenue including } \\
\text { employment-related insurance } \\
\text { contributions }\end{array}$ \\
\hline $\begin{array}{l}\text { Coverage and } \\
\text { financing of } \\
\text { health care }\end{array}$ & $\begin{array}{l}\text { Coverage is universal: } \\
\text { SHI } \\
\text { VHI } \\
\text { Out-of-pocket expenses } \\
\text { Patients pay up-front for services, } \\
\text { and a proportion is reimbursed } \\
\text { by government } \\
\text { Cost-sharing takes three forms: } \\
\text { Co-insurance } \\
\text { Co-payments } \\
\text { Balance billing }\end{array}$ & $\begin{array}{l}\text { Coverage is universal for all legal } \\
\text { residents [57]: } \\
\text { SHI }-86 \% \text { of population } \\
\text { PHI }-11 \% \\
\text { Special programs }\end{array}$ & $\begin{array}{l}\text { Coverage is universal and is mostly } \\
\text { free at point of use [42] } \\
\text { Outpatient prescription drugs are } \\
\text { subject to a co-payment in } \\
\text { England [42]. Prescriptions are } \\
\text { free in Scotland, Wales, and } \\
\text { Northern Ireland [647] } \\
\text { Drugs prescribed in NHS hospitals } \\
\text { are free [42] }\end{array}$ \\
\hline $\begin{array}{l}\text { Private insurance } \\
\text { role }\end{array}$ & $\begin{array}{l}\text { Approx. } 90 \% \text { of people buy or } \\
\text { receive government vouchers for } \\
\text { cost-sharing; some non-covered } \\
\text { benefits [53] }\end{array}$ & $\begin{array}{l}\text { Approx. } 11 \% \text { of people opt-out of } \\
\text { SHI system for private coverage } \\
\text { only [57]. Some complementary } \\
\text { (minor benefit exclusion from } \\
\text { statutory scheme, copayments) } \\
\text { and supplementary coverage } \\
\text { (improved amenities) }\end{array}$ & $\begin{array}{l}\text { Approx. } 11 \% \text { of people buy private } \\
\text { insurance for private facilities, } \\
\text { mainly for elective surgery and } \\
\text { consultations with specialists } \\
\text { [42] }\end{array}$ \\
\hline Caps on cost sharing & $\begin{array}{l}\text { None [53] } \\
€ 50 \text { cap on deductibles for } \\
\text { consultations and services }\end{array}$ & $\begin{array}{l}\text { Yes [57] } \\
2 \% \text { of income; } 1 \% \text { of income for } \\
\text { chronically ill and low-income } \\
\text { people }\end{array}$ & $\begin{array}{l}\text { No general cap for out-of-pocket } \\
\text { expenses } \\
\text { Prepayment certificate with } £ 29 \\
\text { per } 3 \text { months or } £ 104 \text { per year } \\
\text { ceiling for those needing a large } \\
\text { number of prescription drugs }\end{array}$ \\
\hline $\begin{array}{l}\text { Exemptions on cost } \\
\text { sharing and } \\
\text { low-income } \\
\text { protection }\end{array}$ & $\begin{array}{l}\text { Exemption for low-income } \\
\text { individuals, chronically ill and } \\
\text { disabled, and children [53] }\end{array}$ & $\begin{array}{l}\text { Children and adolescents aged }<18 \\
\text { years exempt [57] }\end{array}$ & $\begin{array}{l}\text { Drug cost-sharing exemption for } \\
\text { low-income individuals, older } \\
\text { people, children, pregnant } \\
\text { women and new mothers, and } \\
\text { some disabled/chronically ill } \\
\text { individuals. Financial assistance } \\
\text { with transport costs available to } \\
\text { people on low incomes [42] }\end{array}$ \\
\hline $\begin{array}{l}\text { Provision of health } \\
\text { care services } \\
\text { (primary care, } \\
\text { specialists; } \\
\text { hospital care) }\end{array}$ & $\begin{array}{l}\text { Free to choose any doctor/hospital } \\
\text { Can go direct to specialist (but } \\
\text { referral for most specialist } \\
\text { consultations has to be issued by } \\
\text { a primary care physician or could } \\
\text { lead to incomplete SHI coverage } \\
\text { for the patient) [53] }\end{array}$ & $\begin{array}{l}\text { Easy access to specialists but } \\
\text { gatekeeping system is now } \\
\text { encouraged }\end{array}$ & $\begin{array}{l}\text { Mainly through GPs who act as } \\
\text { gatekeepers for secondary care } \\
\text { [42] } \\
\text { Patients can choose which hospital } \\
\text { to visit, and the government has } \\
\text { introduced the right to choose } \\
\text { a particular specialist within } \\
\text { a hospital (albeit not yet fully } \\
\text { implemented) [42] }\end{array}$ \\
\hline
\end{tabular}


Table 4

(Continued)

$\frac{\text { France }}{\text { Mental health (including long-term medical and social care) }}$

Mental health care Services provided by health care sector take the form of both public and private care in both outpatient and inpatient settings. Emphasis is on communitybased provision [53]

Germany

Ambulatory psychiatrists have been made coordinators of a new set of SHI-financed benefits called "sociotherapeutic care" (which requires referral by a GP), to encourage the chronically mentally ill to use necessary care and to avoid unnecessary hospitalizations [57]

Long-term (social) care (residential care, home-based care)
Long-term care for elderly and disabled belongs to the "health and social care sector". Care may be provided at home or in residences [53]

Home care is provided mainly by self-employed physicians and nurses, with some community nursing services (SSIAD). These services are needs based

Residential care is provided in retirement homes and long-term care units

SHI covers medical care costs, but families incur the costs for housing. Temporary care is covered without restrictions

Long-term care beds in institutions and hospitals: 59.0 per 1,000 population aged $\geq 65$ years [49]
Long-term care covered by a separate insurance scheme (LTCI) [57]

This is mandatory and usually provided by the same insurer as health insurance (has a similar public-private mix)

Anybody with a physical or mental illness or disability (who has contributed for at least 2 years) can apply for benefits under this scheme

Both home care and institutional care are delivered by private providers

Long-term care beds in institutions and hospitals: 53.1 per 1,000 population aged $\geq 65$ years [49]
UK

Integral part of NHS; serious illness treated through mental health or hospital trusts. Part of this is supported through community-based staff. A quarter of mental health care hospital-based services are provided by the private sector [42]

Long-term care is provided by the health and social care sector and includes both residential care and home care [42]

State-funded social care is not universal

NHS pays for some long-term care

Residential and home care is needs-tested and means-tested

Most long-term care is provided by local authorities and private sector; funded by mix of public-private payments

Long-term care beds in institutions and hospitals: 49.5 per 1,000 population aged $\geq 65$ years [49]
Financial support
LTCI benefits are dependent on evaluation of individual need. Persons evaluated as in need of care are assigned to one of three levels of care (I, II, or III) depending on the extent of the need for care [57]. Persons who need general care and domestic help as a result of dementia but who have not reached Care Level I are allocated to Care Level 0 and are entitled to a range of benefits, which are broader since 1 Jan 2015 after the First Act to Strengthen Long-Term Care was passed [65]

Beneficiaries can choose in-kind benefits or cash payments

\begin{tabular}{|c|c|}
\hline $\begin{array}{l}\text { National dementia } \\
\text { strategy }\end{array}$ & $\begin{array}{l}\text { FAP supporting caregivers and } \\
\text { ensuring patients' quality of life } \\
\text { in addition to enforcing } \\
\text { compliance with guidelines and } \\
\text { promoting evidence-based } \\
\text { practice } 28]\end{array}$ \\
\hline
\end{tabular}

No national dementia plan but Alliance for People with Dementia: The Fields of Action [32, 33]

S3 Guidelines for the diagnosis and treatment of Alzheimer's disease $[30,31]$
Patient Attendance Allowance

Carer's Allowance
England, Scotland, Ireland, and Wales have separate national dementia strategies [34-37]
NICE guidelines and quality standards for dementia care are available [38, 39, 40]


Table 4

(Continued)

\begin{tabular}{|c|c|c|c|}
\hline & France & Germany & UK \\
\hline $\begin{array}{l}\text { Dementia care } \\
\text { services } \\
\text { (community } \\
\text { based) }\end{array}$ & $\begin{array}{l}\text { Health and social care services, } \\
\text { including community-based } \\
\text { services are well-established and } \\
\text { utilized for dementia } \\
\text { management } \\
\text { The FAP facilitates caregiver } \\
\text { support, including respite care, } \\
\text { consolidates caregiver rights and } \\
\text { training, and improves caregiver } \\
\text { health monitoring }\end{array}$ & $\begin{array}{l}\text { Community-based services overall } \\
\text { are less frequently used than } \\
\text { those in France }\end{array}$ & $\begin{array}{l}\text { Community-based services overall } \\
\text { are less frequently used } \\
\text { compared with France } \\
\text { National dementia strategies } \\
\text { improve the care, support, and } \\
\text { advice offered to people with } \\
\text { dementia and their caregivers } \\
\text { [45] }\end{array}$ \\
\hline $\begin{array}{l}\text { Organization of care } \\
\text { and support for } \\
\text { people with } \\
\text { dementia }^{b}\end{array}$ & $\begin{array}{l}\text { Medical care for people with } \\
\text { dementia is reimbursed at } 100 \%\end{array}$ & $\begin{array}{l}\text { Care for dementia available } \\
\text { through LTCI } \\
\text { Many services and nursing homes } \\
\text { do not respond specifically to the } \\
\text { needs of patients with dementia } \\
\text { A small, growing number of } \\
\text { provisions for people with } \\
\text { dementia and caregivers for } \\
\text { ethnic minorities in Germany are } \\
\text { available (e.g., AWO } \\
\text { Landesverband) }\end{array}$ & $\begin{array}{l}\text { A wide range of health and social } \\
\text { services are provided by the NHS } \\
\text { specifically for patients with } \\
\text { dementia and their caregivers }\end{array}$ \\
\hline $\begin{array}{l}\text { Home care for } \\
\text { people with } \\
\text { dementia }^{b} \\
\text { Residential care for } \\
\text { people with } \\
\text { dementia }^{b}\end{array}$ & $\begin{array}{l}\text { Home care and support plan is } \\
\text { available and coordinated by the } \\
\text { GP in conjunction with } \\
\text { a specialist (as applicable) } \\
\text { Recommendations available } \\
\text { (ANESM) that cover life habits, } \\
\text { washing, nutrition, mobility, } \\
\text { sleep, social life, security, } \\
\text { dignity, well-being, and } \\
\text { autonomy }\end{array}$ & $\begin{array}{l}\text { Social and healthcare professionals } \\
\text { are involved in the provision of } \\
\text { care and support to people with } \\
\text { dementia in residential care or at } \\
\text { home }\end{array}$ & $\begin{array}{l}\text { Social and healthcare professionals } \\
\text { are involved in the provision of } \\
\text { care and support to people with } \\
\text { dementia in residential care or at } \\
\text { home }\end{array}$ \\
\hline $\begin{array}{l}\text { Support for informal } \\
\text { caregivers to } \\
\text { patients with } \\
\text { dementia }^{b}\end{array}$ & $\begin{array}{l}\text { Support for informal caregivers is } \\
\text { implemented via the FAP. Issues } \\
\text { addressed include respite, } \\
\text { training, counseling and support, } \\
\text { and case management }\end{array}$ & $\begin{array}{l}\text { Support for informal caregivers in } \\
\text { the context of LTCI is addressed } \\
\text { in national policies specific to } \\
\text { respite ( } \S 39 \text { SGB XI, } \S 41 \text { SGB } \\
\text { XI, } \S 42 \text { SGB XI), training ( } \$ 45 \\
\text { SGB XI), counseling and support } \\
\text { ( } § 7 \text { SGB XI), and case } \\
\text { management ( } \S \S 7,92 \text { SGB XI) } \\
\text { Since } 2015 \text {, the First Act to } \\
\text { Strengthen Long-term Care has } \\
\text { expanded the benefits to support } \\
\text { caregiving relatives [65] }\end{array}$ & $\begin{array}{l}\text { Support for informal caregivers is } \\
\text { addressed in national policies of } \\
\text { England, Wales, and Northern } \\
\text { Ireland }[34,36,37], \text { and in } 2010 \text {, } \\
\text { the Scottish Government } \\
\text { published Caring Together: The } \\
\text { Carers Strategy for Scotland } \\
2010-15 \text { [66] }\end{array}$ \\
\hline
\end{tabular}

\footnotetext{
${ }^{a}$ Much of the general information is adapted from Table 1 in International Profiles of Health Care Systems, 2014 [67]. ${ }^{b}$ Most of the dementia-specific information is taken from [68]. ADL, activities of daily living; ANESM, Agence Nationale de l'Evaluation et de la qualité des établissements et Services Sociaux et Médico-Sociaux; APA, Allocation Personnaliseé d'Autonomie; DGPPN, German Society for Psychiatry, Psychotherapy and Neurology; FAP, French Alzheimer Plan; GP, general practitioner; LTCI, long-term care insurance; NHS, National Health Service; NICE, National Institute for Health and Care Excellence; PHI, private health insurance; SGB XI, German care insurance law (Sozialgesetzbuch XI); SHI, statutory health insurance; SSIAD, Services de Soins Infirmiers á Domicile; VHI, voluntary health insurance.
}

Our analyses used country-specific unit costs and examined differences in resource use between countries after controlling for key patient and caregiver characteristics. We will interpret and explain our findings in the context of each country's health and social care systems, or strategies for dementia care that were in place at the time the GERAS study was performed (years 2010-2013) (Table 4).

\section{Informal caregiver time}

As caregiver time was the predominant resource use item driving total societal costs in all three coun- 
tries, we have tried to identify any country differences in the composition of informal care. The unit costs applied for informal caregiver time were lower in the UK than in the other two countries (see Supplementary Table 1). Thus, the higher percentage of total costs in the UK is likely to be due to more time spent caring.

Indeed, caregivers in the UK spent more time on instrumental ADL than caregivers in France and Germany (Table 3), independent of the sex of the caregiver, and indicates a lack of formalized support to assist with daily activities. Informal caregivers in the UK therefore appear to shoulder much of the burden of caring for $\mathrm{AD}$ dementia patients, with less use of community care services and outpatient visits, despite health and social care being largely free at the point of use. This is consistent with a recent report on dementia care in the UK, which stated that informal caregiver time ranged from an estimated 13 hours per week for patients with mild dementia to 46 hours per week for severe dementia and that only $12 \%$ of the 570,000 people living with dementia in England received relevant social care services [23]. Furthermore, a national survey of caregivers of people with dementia in the UK found that a large number are not receiving the support they need from health and care services [24].

French caregivers spent less time on basic ADL than caregivers in the UK. As French patients use more community care services overall, they may be receiving assistance for self-care tasks from external sources, such as district nurses or home helps (as indicated by the greater frequency of district nurse visits and increased likelihood of home aid visits, similar to findings from the ICTUS study [2]). Community-dwelling patients aged over 60 years and needing assistance with ADL in France can receive a means-tested allowance (Allocation Personnalisée d'Autonomie [APA]) to encourage use of professional services [25]. This assistance may also explain why French caregivers missed fewer work days. Although UK patients can receive an Attendance Allowance and caregivers may be eligible for a Carer's Allowance, there is evidence that up to two-thirds of informal caregivers in the UK are not having their needs assessed or needs met once assessed [23]. However, our results show that UK caregivers/patients are more likely to receive financial support than those in the other two countries.

National dementia strategies in each country (France: Neurodegenerative disease plan [26-28]; Germany: Alliance for People with Dementia [29,
30]; UK: country specific national dementia strategies [31-34]) all aim to support informal caregivers and/or facilitate professional services to maintain community living.

\section{Community care services}

The UK had the lowest use of community care services. When looking into individual services, patients in the UK were less likely to receive home aid services than French patients, although UK patients had more time spent on home aid when received. UK patients also used less food delivery and had fewer district nurse visits compared with France and Germany. Knapp et al. [35] remarked on the difficulty of comparing community care services between countries as the services have different definitions and are not equivalent. In 2011, of the people receiving social care services for dementia in England, 58\% received community-based services, while $28 \%$ were in residential care and $14 \%$ in nursing care [23]. Most local authorities charge a means-tested contribution from patients for home care and residential care [36]. Nursing home care is paid for by the National Health Service (NHS) only if the patient has been assessed as fulfilling continuing NHS health care criteria [37]; however, as there is no medical treatment in more advanced AD dementia, the majority of these patients are in social care or self-funded.

In our analysis, the use of day care in the UK was surprisingly low, but this may reflect the $49 \%$ fall in the number of older people using day care centers between 2005/6 and 2012/13 reported by Age UK in their Care in Crisis 2014 briefing document [38] as a result of cuts in funding.

The use of community care services overall was slightly higher in Germany than in the UK but significantly less than in France. German patients were less likely to use transportation services than patients in the other countries, but had a higher use than French patients in those that received these services. German patients were less likely to spend time in temporary accommodation and were less likely to be institutionalized during the 18-month follow-up period of the study than patients in the other two countries. Our results are consistent with previous comparisons of the percentage of the older population living in care homes in these countries [35]. The lower rate of institutionalization among German patients means keeping them living at home for longer, which is an aim of German health care policy and the long-term care insurance system. This and the lack of specific 
geriatric health care services in Germany is likely to impact on utilization of social care/support services as well as costs.

The greater use of community care services in France may indicate that health and social care services are better developed in France and may reflect the benefits offered by the French Alzheimer Plan $[26,28]$. However, patients and caregivers in France were less likely to receive additional financial support than those in the UK. In France, the APA allowance for dependent elderly persons typically covers the general expenses for day care and home help services. In their study of the costs of $\mathrm{AD}$ dementia in France, Gerves et al. [25] found that only 29\% of community-dwelling patients with AD dementia received an APA and concluded that the APA covered only about one-fifth of the total costs of care for $\mathrm{AD}$ dementia patients.

Financial support is not usually included in estimations of total societal costs because it represents transfer costs. Financial support is associated with resource use and informal caregiver time but we only included financial support in our cost calculation if it was higher than the combined costs of community care services, consumables, and structural changes. In a cross-sectional sample of French elderly patients living with mild to moderate AD dementia (PLASA study), patient financial support was associated with greater use of formal care (especially home help) and less use of informal care [39]. Additionally, our sample of French patients was also more likely to have stays in temporary accommodation than German patients, possibly due to the provision of respite care under measure one of the French Alzheimer Plan [28].

\section{Health care resource use}

Patients in the UK had fewer GP visits, and a lower percentage of patients in the UK consulted neurologists or physiotherapists, during the 18-month period than patients in the other two countries (data available upon request). Neurologists in the UK rarely see AD dementia patients, but may see those with early-onset dementia. More patients in the UK consulted a psychiatrist compared with those in France (data available upon request), and, when seen, had more visits to a psychiatrist than French patients. These observations may depend on the specialist that patients are seeing in the memory clinic. The specialty of the investigators participating in the GERAS study varied between countries [8]; in the UK,
$79 \%$ were psychiatrists and $16 \%$ were geriatricians, whereas in France, 64\% were geriatricians, and in Germany, $49 \%$ were neurologists and $41 \%$ were psychiatrists. Patients in the UK used fewer outpatient resources overall than patients in the other two countries, and spent fewer days in hospital than French patients, who also spent more days in hospital than patients in Germany.

In the UK, health care is mainly provided by the NHS, which is largely free at the point of use, including primary care, inpatient and outpatient hospital care, and some long-term health care (e.g., for those with continuing medical or skilled nursing needs) [36]. Also, medication is free to people aged over 60 years. The first point of contact for most patients is the GP, who plays a gatekeeping role in determining access to specialist services.

Our findings are consistent with the high use of outpatient services (88\%) reported previously for home-living German AD dementia patients [40]. They are probably the result of the broad range of health care services offered in Germany and the easy access to specialists.

In France, health care is largely financed by government national health insurance [41]. Patients usually pay up-front for the service provided and then a proportion of the payment is reimbursed immediately by the government [42] with $100 \%$ of medical care costs refunded back to patients in cases of costly or long-term ailments [41].

No difference in whether AD medication was taken (or not) was observed between countries, although the UK had the lowest use. Further analyses by medication type have shown a few differences between countries (e.g., less use of memantine in the UK, which is in line with country-specific treatment guidelines $[43,44]$ and a systematic review in Germany [45]). However, AD medication use accounts for only a small proportion of total costs in each country (8-14\%; Supplementary Table 2).

\section{Caregiver support}

An emerging point from this study is that caregiver support may be important in determining informal caregiver time and, ultimately, cost. As caregiver time is such a large component of the societal costs associated with $\mathrm{AD}$ dementia, better support and interventions for caregivers of community-dwelling patients have the potential to reduce societal costs. The French Alzheimer Plan [28] highlights several strategies for caregiver support, including respite 
care, consolidating caregiver rights and training, and improving caregiver health monitoring. This type of support may have contributed to French caregivers missing the fewest work days in our study. Germany does not currently have a national dementia plan, but one of the four fields of action in the Alliance for People with Dementia is to provide support for people with dementia and their families [30]. In the UK, the national dementia strategies for England [31], Scotland [32], Wales [34], and Northern Ireland [33] all aim to improve the care, support, and advice offered to people with dementia and their caregivers.

\section{Study strengths}

Our study has several strengths. We recruited a large sample of community-dwelling patients with AD dementia and used longitudinal data collected over 18 months. We used a standardized instrument (RUD) for collecting resource use data across the three participating countries, which allowed us to compare resource utilization between countries. To enable us to reflect total societal costs, gaps in resource use were met by asking specific questions on out-of-pocket expenses, such as structural changes required or consumables purchased by families. Additional payments to the patient or caregiver for the task of caregiving were also collected, but cost estimates were specified to avoid double counting. We adjusted our models for several patient and caregiver characteristics, and analyzed country differences in resource use by two methods: first, we used repeated measures analysis of all available data at each 6-month visit; and second, we pooled the data from patients with data at all three follow-up visits (completers). The results from these models generally gave similar findings. Years of education for the patient were not included in the current models because we did not find this variable to be associated with resource use in a previous publication [46]. Country differences in resource use still existed after additional analyses adjusted for patient years of education (data available upon request).

\section{Study limitations}

This study has several limitations. First, the GERAS study population was a clinic-based sample, and all patients were living in the community. Information was available over 18 months of follow-up or until patients left the study, some due to institutionalization or death. Thus, our analyses of resource use are only for community-dwelling patients and cannot be extended to patients living permanently in residential care, as resource utilization patterns differ between community-dwelling and institutionalized dementia patients [47]. Also, the sample was enrolled as approximately equal numbers of patients with mild, moderate, and MS/S AD dementia, so does not reflect the general prevalence by disease severity and, therefore, is not fully representative of all patients with $\mathrm{AD}$ dementia. However, our resource use analyses were adjusted for AD dementia severity. Second, as resource use was collected at each visit via an interview with the caregiver, it may be subject to recall bias. However, with prospective follow-up and the use of diary records, this bias has been minimized as much as possible. Also, we only analyzed time spent providing informal care by the primary caregiver, which could lead to an underestimation of informal caregiving time as it is possible that many patients receive care from several family members.

\section{Conclusions}

This study showed that differences in contributions of the components of societal cost between France, Germany, and the UK in the care of $\mathrm{AD}$ dementia patients reflected differences in the utilization of available resources across these countries. All patients were community dwelling at baseline, with rates of institutionalization over the 18-month follow-up period dependent on baseline AD dementia severity. Informal caregiver time was the main contributor to societal costs. Caregiver time on basic and instrumental ADL differed across countries, some of which may be explained by use of community care services. Other differences in resource use across countries reflected the health and social care systems but had limited influence on societal cost differences.

\section{ACKNOWLEDGMENTS}

The study was supported by Eli Lilly and Company. CR, MH, and MB are employees of Eli Lilly and Company. JMA, JMH, AW, GB, RD, RWJ, and BV have received financial compensation from Eli Lilly for participation on the GERAS Advisory Board.

The authors wish to thank all investigators who participated in the study.

The authors would like to acknowledge Dr. Deirdre Elmhirst and Dr. Claire Lavin (Rx Communications, Mold, UK) for medical writing assistance with the 
preparation of this article, funded by Eli Lilly and Company.

Authors' disclosures available online (http://j-alz. com/manuscript-disclosures/16-0449r2).

\section{SUPPLEMENTARY MATERIAL}

The supplementary material is available in the electronic version of this article: http://dx.doi.org/ 10.3233/JAD-160449.

\section{REFERENCES}

[1] Jönsson L, Wimo A (2009) The cost of dementia in Europe. a review of the evidence and methodological considerations. Pharmacoeconomics 27, 391-403.

[2] Gustavsson A, Jonsson L, Rapp T, Reynish E, Ousset PJ, Andrieu A, Cantet C, Winblad B, Vellas B, Wimo A, on behalf of the ICTUS Study Group (2010) Differences in resource use and costs of dementia care between European countries: Baseline data from the ICTUS study. J Nutr Health Aging 14, 648-654.

[3] Mauskopf J, Racketa J, Sherrill E (2010) Alzheimer's disease: The strength of association of costs with different measures of disease severity. J Nutr Health Aging 14, 655663.

[4] Mesterton J, Wimo A, By A, Langworth S, Winblad B, Jönsson L (2010) Cross sectional observational study on the societal costs of Alzheimer's disease. Curr Alzheimer Res 7, 358-367.

[5] Quentin W, Riedel-Heller SG, Luppa M, Rudolph A, Konig HH (2010) Cost-of-illness studies of dementia: A systematic review focusing on stage dependency of costs. Acta Psychiatr Scand 121, 243-259.

[6] Leicht H, Heinrich S, Heider D, Bachmann C, Bickel H, van den Bussche H, Fuchs A, Luppa M, Maier W, Mösch E, Pentzek M, Rieder-Heller SG, Tebarth F, Werle J, Weyerer S, Wiese B, Zimmermann T, König HH; AgeCoDe study group (2011) Net costs of dementia by disease stage. Acta Psychiatr Scand 124, 384-395.

[7] Rapp T, Andrieu S, Molinier L, Grand A, Cantet C, Mullins CD, Vellas B (2012) Exploring the relationship between Alzheimer's disease severity and longitudinal costs. Value Health 15, 412-419.

[8] Wimo A, Reed CC, Dodel R, Belger M, Jones RW, Happich M, Argimon JM, Bruno G, Novick D, Vellas B, Haro JM (2013) The GERAS study: A prospective observational study of costs and resource use in community dwellers with Alzheimer's disease in three European countries-study design and baseline findings. J Alzheimers Dis 36, 385-399.

[9] Schwarzkopf L, Menn P, Kunz S, Holle R, Lauterberg J, Marx P, Mehlig H, Wunder S, Leidl R, Donath C, Graessel E (2011) Costs of care for dementia patients in community setting: An analysis for mild and moderate disease stage. Value Health 14, 827-835.

[10] Darbá J, Kaskens L, Lacey L (2015) Relationship between global severity of patients with Alzheimer's disease and costs of care in Spain; results from the co-dependence study in Spain. Eur J Health Econ 16, 895-905.

[11] Gillespie P, O'Shea E, Cullinan J, Buchanan J, Bobula J, Lacey L, Gallagher D, Mhaolain AN, Lawlor B for the Enhancing Care in Alzheimer's Disease (ECAD) Study
Team (2015) Longitudinal costs of caring for people with Alzheimer's disease. Int Psychogeriatr 27, 847-856.

[12] Schaller S, Mauskopf J, Kriza C, Wahlster P, KolominskyRabas PL (2015) The main cost drivers in dementia: A systematic review. Int J Geriatr Psychiatry 30, 111-129.

[13] McKhann G, Drachman D, Folstein M, Katzman R, Price D, Stadlan EM (1984) Clinical diagnosis of Alzheimer's disease: Report of the NINCDS-ADRDA Work Group under the auspices of Department of Health and Human Services Task Force on Alzheimer's Disease. Neurology 34, 939-944.

[14] Folstein MF, Folstein SE, McHugh PR (1975) “Mini-mental state." A practical method for grading the cognitive state of patients for the clinician. J Psychiatric Res 12, 189-198.

[15] Rosen WG, Mohs RC, Davis KL (1984) A new rating scale for Alzheimer's disease. Am J Psychiatry 141, 1356-1364.

[16] Galasko D, Schmitt F, Thomas R, Jin S, Bennett D; Alzheimer's Disease Cooperative Study (2005) Detailed assessment of activities of daily living in moderate to severe Alzheimer's disease. J Int Neuropsychol Soc 11, 446-453.

[17] Cummings JL (1997) The Neuropsychiatric Inventory: Assessing psychopathology in dementia patients. Neurology 48(Suppl 6), 10-16.

[18] Zarit SH, Reever KE, Bach-Peterson J (1980) Relatives of the impaired elderly: Correlates of feelings of burden. Gerontologist 20, 649-655.

[19] Wimo A, Wetterholm AL, Mastey V, Winblad B (1998) Evaluation of the healthcare resource utilization and caregiver time in anti-dementia drug trials. The Health Economics of Dementia, Wimo A, Jönsson B, Karlsson G, Winblad B, Eds. John Wiley and Sons, London, pp. 465-499.

[20] Wimo A, Nordberg G (2007) Validity and reliability of assessments of time. Comparisons of direct observations and estimates of time by use of the resource utilization in dementia (RUD)-instrument. Arch Gerontol Geriatr 44, 71-81.

[21] Wimo A, Jonsson L, Zbrozek A (2010) The resource utilization in dementia (RUD) instrument is valid for assessing informal care time in community-living patients with dementia. J Nutr Health Aging 14, 685-690.

[22] Wimo A, Gustavsson A, Jonsson L, Winblad B, Hsu M-A, Gannon B (2013) Application of Resource Utilization in Dementia (RUD) instrument in a global setting. Alzheimers Dement 9, 429-435.

[23] The Health Foundation (2011) Spotlight on Dementia Care: A Health Foundation Improvement Report. Health Foundation, London, http://www.health.org.uk/sites/default/files/ SpotlightOnDementiaCare_fullversion.pdf, Accessed on January 13, 2016.

[24] Newbronner L, Chamberlain R, Borthwick R, Baxter M, Glendenning C (2013) A Road Less Rocky - Supporting Carers of People with Dementia, http://www.carers.org/ sites/default/files/dementia_report_road_less_rocky_final_ low.pdf, Accessed on March 24, 2015.

[25] Gerves C, Chauvin P, Bellanger MM (2014) Evaluation of full costs of care for patients with Alzheimer's disease in France: The predominant role of informal care. Health Policy 116, 114-122.

[26] Alzheimer Europe (2016) France - National Dementia Strategies, http://www.alzheimer-europe.org/EN/Policy-inPractice2/National-Dementia-Strategies/France\#fragment5, Accessed on June 16, 2016.

[27] Pimouguet C, Bassi V, Somme D, Lavallart B, Helmer C, Dartigues JF (2013) The 2008-2012 French Alzheimer 
plan: A unique opportunity for improving integrated care for dementia. J Alzheimers Dis 34, 307-314.

[28] République Française (2008) National Plan for "Alzheimer and Related Diseases" 2008-2012, http://www.plan-alzhei mer.gouv.fr/IMG/pdf/Plan_Alzheimer_2008-2012_uk.pdf, Accessed on September 17, 2015.

[29] Alzheimer Europe (2014) Germany: National Dementia Plans. http://www.alzheimer-europe.org/Policy-in-Practice 2/National-Dementia-Plans/Germany, Accessed on December 7, 2015.

[30] German Federal Ministry for Family Affairs, Senior Citizens, Women and Youth Public Relations Division and German Federal Ministry of Health (2014) Alliance for People with Dementia: The Fields of Action. http://www.allianz-fuer-demenz.de/fileadmin/de.allianzfuer-demenz/content.de/downloads/BF1501_001_AllianzNationale_Demenzstrategie_EN_RZ.pdf, Accessed on December 7, 2015.

[31] Alzheimer's Society (2012) Dementia 2012: A National Challenge, Alzheimer's Society, London, https://www. alzheimers.org.uk/site/scripts/download_info.php?fileID= 1389, Accessed on January 15, 2016.

[32] Scottish Government (2013) Scotland's National Dementia Strategy 2013-2016, http://www.gov.scot/Resource/0042/ 00423472.pdf, Accessed on March 26, 2015.

[33] Department of Health, Social Services and Public Safety (2011) Improving Dementia Services in Northern Ireland a Regional Strategy, http://www.alzheimer-europe.org/con tent/download/35068/235414/file/Northern\%20Ireland\%20 dementia\%20strategy\%20-\%20easy\%20read\%20version. pdf, Accessed on January 15, 2016.

[34] Welsh Assembly Government (2011) National Dementia Vision for Wales, http://gov.wales/docs/dhss/publications/ 110302dementiaen.pdf, Accessed on March 26, 2015.

[35] Knapp M, Comas-Herrera, Somani A, Banerjee S (2007) Dementia: International Comparisons, http://www.pssru.ac. uk/pdf/dp2418.pdf, Accessed on March 31, 2015.

[36] Thorlby R, Arora S (2015) The English health care system, 2014. In International Profiles of Health Care Systems, 2014, Mossialos E, Wenzl M, Osborn R, Anderson C, eds. The Commonwealth Fund, pp. 43-52, http://www.common wealthfund.org/ /media/files/publications/fund-report/ 2015/jan/1802_mossialos_intl_profiles_2014_v7.pdf, Accessed on August 12, 2015.

[37] Alzheimer Europe (2014) United Kingdom - England, Social Support Systems, http://www.alzheimer-europe.org/ Policy-in-Practice2/Country-comparisons/Social-supportsystems/United-Kingdom-England, Accessed on January 22, 2015.

[38] Age UK (2014) Care in Crisis 2014, http://www.ageuk. org.uk/Documents/EN-GB/For-professionals/Research/ CareInCrisis 2014\%20FINAL.pdf?dtrk=true, Accessed on February 17, 2015.
[39] Rapp T, Grand A, Cantet C, Andrieu S, Coley N, Portet F, Vellas B (2011) Public financial support receipt and nonmedical resource utilization in Alzheimer's disease results from the PLASA study. Soc Sci Med 72, 1310-1316.

[40] Reese JP, Hessmann P, Seeberg G, Henkel D, Hirzmann P, Rieke J, Baum E, Dannhoff F, Müller MJ, Jessen F, Geldsetzer MB, Dodel R (2011) Cost and care of patients with Alzheimer's disease: Clinical predictors in German health care settings. J Alzheimers Dis 27, 723-736.

[41] Durand-Zaleski I (2015) The French health care system, 2014. In International Profiles of Health Care Systems, 2014, Mossialos E, Wenzl M, Osborn R, Anderson C, eds. The Commonwealth Fund, pp. 53-62, http://www.common wealthfund.org/ /media/files/publications/fund-report/ 2015/jan/1802_mossialos_intl_profiles_2014_v7.pdf, Accessed on August 12, 2015.

[42] Civitas (2013) Healthcare Systems: France, http://www. civitas.org.uk/content/files/france.pdf, Accessed on January $15,2016$.

[43] National Institute of Health and Care Excellence, NICE (2011) Donepezil, Galantamine, Rivastigmine and Memantine for the Treatment of Alzheimer's Disease, https://www. nice.org.uk/guidance/ta217, Accessed on February 19, 2015.

[44] Haute Autorité de Santé (HAS) (2011) Recommendation of Good Practice. Alzheimer's Disease and Related Disorders: Diagnosis and Management. December 2011, http://www.has-sante.fr/portail/upload/docs/application/ pdf/2011-12/recommandation_maladie_d_alzheimer_et_mal adies_apparentees_diagnostic_et_prsie_en_charge.pdf, Accessed on June 15, 2015.

[45] Institute for Quality and Efficiency in Health Care IQWiG (2009) Memantine in Alzheimer's Disease. Commission No. A05-19C. Executive Summary, https://www.iqwig. de/download/A05-19C_Executive_Summary_Memantine in_Alzheimers_disease.pdf, Accessed on June 15, 2015.

[46] Dodel R, Belger M, Reed C, Wimo A, Jones RW, Happich M, Argimon JM, Bruno G, Vellas B, Haro JM (2015) Determinants of societal costs in Alzheimer's disease: GERAS study baseline results. Alzheimers Dement 11, 933-945.

[47] Schwarzkopf L, Menn P, Leidl R, Graesser E, Holle R (2013) Are community-living and institutionalized dementia patients cared for differently? Evidence on service utilization and costs of care from German insurance claims data. BMC Health Serv Res 13:2, doi:10.1186/1472-6963-13-2, http://www.biomedcentral.com/1472-6963/13/2, Accessed on August 12, 2015. 